\title{
First Year ESL Students Developing Critical Thinking: Challenging the Stereotypes
}

\author{
Yongyan Li \\ Correspondence: Yongyan Li, Faculty of Education, University of Hong Kong, China. E-mail: yongyan @ hku.hk
}

Received: June 15, 2013 Accepted: July 3, 2013 Online Published: July 10, 2013

doi:10.11114/jets.v1i2.153

URL: http://dx.doi.org/10.11114/jets.v1i2.153

\begin{abstract}
Reporting a case study of two high-achieving Chinese students studying at a university in Hong Kong, this paper presents evidence that poses an anti-thesis to the stereotypes of first year university students as holding naïve beliefs about learning and of 'Chinese learners' as lacking in critical thinking. Many studies have examined Chinese students' learning experiences within local educational contexts, yet we know very little what beliefs individual Chinese ESL students hold about learning and writing in an English-dominant university especially in their early stage of studying at such an institution, and how their beliefs are reflected in what they actually do in their writing. This paper aims to illuminate a connection between two high-achieving Chinese students' beliefs about learning/writing in the university and what they did in a written assignment in an introductory course of political science, especially in terms of their use of authorship strategies as they wrote from sources. The data were collected through interviews and gathering the students' notes, process logs, papers, source texts, as well as the relevant materials of the political science course. The study revealed that for both students the essence of university learning and writing consisted in independent and critical thinking, and writing with a clear view and sound logic; and they both imprinted authorship into their papers, by proposing revised theories on their selected topics and fitting sources into their own organizational frameworks.
\end{abstract}

Keywords: first year university students, self-regulated learner, authorship strategies in writing

\section{Introduction}

Chinese students' learning experience has been a topic engaging wide interest in the past decade (Chan \& Rao, 2009; Watkins \& Biggs, 2001). Increasingly a traditional 'large culture' approach, which tends to construct a deficit model of 'Chinese learners' as passive, fond of rote memorization, and incapable of critical thinking, is giving way to a 'small culture' (Holliday 1999) view that looks into Chinese students' learning experiences within local educational contexts (e.g., Clark \& Gieve, 2006; Grimshaw, 2007). Such contextualized research has the potential to challenge the stereotypes of learners as defined by their ethnicities. Research conducted in this spirit has included the study of Chinese students' English as a second language (ESL) experience in Anglophone settings, specifically, their struggles in adapting to the English academic discourse and culture at Anglophone universities (e.g., Cadman, 1997; Hayes \& Introna, 2005; Leki, 2007). Yet not sufficiently addressed in this line of work is perhaps what beliefs individual Chinese ESL students, in their early stage of studying in an English-dominant institution, hold about learning and writing in the university, and how their beliefs are reflected in what they actually do in their writing. The study to be reported in this paper aimed to address this gap in the literature by using a naturalistic qualitative research methodology that involved two high-achieving first year Chinese students studying at an English-medium university in Hong Kong.

\section{Literature Review}

\subsection{University Students' Beliefs about Learning}

Previous research has revealed that university students' beliefs about learning and knowing, or 'epistemological beliefs' to use Schommer's (1993) term, are developmental, display individual variations among the students at the same level of study, and can potentially predict academic performance (Cano, 2005; Pintrich \& de Groot, 1990). From a developmental perspective, compared with advanced year students, early year university students have been found to have 'naïve' or unsophisticated beliefs about learning: that knowledge is handed down from authority and learning is primarily about learning facts (e.g., Perry, 1970; Pintrich, 2002; Schommer, 1993). At 
the same time, however, there is clear evidence that early year students can also hold quite sophisticated views of learning, which tend to overlap their course professors' expectations and account for their academic success (Brownlee et al., 2009; Simpson \& Nist, 1997; Sommers \& Saltz, 2004).

University students' beliefs about learning has been typically studied by educational psychologists through questionnaires (e.g., Perry, 1970; Schommer, 1993; White \& Bruning, 2005) or interviews (e.g., Brownlee et al., 2009), an exception being Simpson and Nist's (1997) ethnographic study of the academic literacy behaviors of some students of different achievement levels in a history course (with over $90 \%$ of the attending students being freshmen and sophomores) at a US university. In their study, they found high-performance students typically engage with key ideas and perspectives, take personal responsibility for their learning, study assigned readings for ideas rather than for facts, and are ready to adjust their study strategies according to their interpretation of the professor's expectations.

\subsection{University Students' Beliefs about and Approaches to Writing}

Students' beliefs about learning and their beliefs about writing tend to be in close alignment, with correspondence seen in the pairs of labels proposed by researchers to describe students' beliefs about learning and about writing. For instance, Muis (2004) distinguished between availing and non-availing beliefs about learning, i.e., beliefs that help or else hinder learning; while White and Bruning (2005) labeled the implicit writing beliefs held by student writers as transactional beliefs which imply higher cognitive and affective engagement with the writing task, versus transmissional beliefs which involve limited engagement. A student's beliefs regarding writing indicate the relationship that he/she set between himself/herself and the writing task, shape his/her writing process, and are predictive of the quality of the writing outcome (e.g., Biggs, 1999; Lavelle \& Zuercher, 2001; Pajaresa, 2003; White \& Bruning, 2005). For example, in their study with a cohort of cross-year undergraduate students enrolled in an introductory educational psychology course, White and Bruning (2005) found that "students with high transactional beliefs scored high on idea-content development, organization, voice, sentence fluency, conventions, and overall writing quality" (p. 166).

Longitudinal research in particular has linked the purposes that university students bring to writing activities to their intellectual development (e.g., Sommers \& Saltz 2004; Sternglass, 1997). Sommers and Saltz (2004), for instance, based on their longitudinal study at Harvard University, pointed out that how students handle freshman year writing is crucial in activating (or not) personal transformation; and that those students who eventually have the biggest gains in intellectual development through writing are the ones who see larger purposes in their writing activities than just for completing assignments.

\subsection{University Students' Authorship Strategies in Writing from Sources}

The literature on students' beliefs about and approaches to writing has rarely specifically looked into students' practices of writing from sources, although there exists a separate body of literature on the latter. In particular, researchers have shown that a student's source-use practice in a piece of writing and the extent to which his/her authorial voice comes out in the writing index his/her epistemological stance vis-à-vis their source texts (e.g., Abasi et al., 2006; Baynham, 1999; Geisler, 1991). Geisler (1991), for example, compared how two novices (first year students who have not taken a philosophy course before) and two experts (a PhD student of philosophy and a recent $\mathrm{PhD}$ graduate of philosophy) completed a philosophy essay based on a set of provided readings. It was found that the novices set themselves a task of seeking and retelling truth, treating the provided collection of readings in conglomeration without distinguishing between authors with varied views; while the experts organized their writing in a much more sophisticated manner, moving toward their own views by eliminating in sequence contestable claims made by the individual authors in their readings.

Although early year university students have been typically reported as having a weak authorial voice (e.g., Abasi et al., 2006; Nelson \& Hayes, 1988), study of successful early year student writers has provided evidence to the contrary (e.g., Greene, 1995; Sommers \& Saltz, 2004). A range of authorship strategies adopted by successful student writers in performing source-based writing tasks in the university, irrespective of the year of study, can be enumerated on the basis of previous literature (e.g., Abasi et al., 2006; Baynham, 1999; Connor \& Kramer, 1995; Geisler, 1991; Greene, 1993, 1995; Kaufer \& Geisler, 1989; Higgins 1993; Nelson \& Hayes, 1988; Penrose \& Geisler, 1994). Specifically, successful student writers may do the following:

- Regard knowledge as constructed and source material as contestable

- Handle sources analytically and interpretively

- Attend to the fact that sources are variedly authored and disagreements of views exist

- Pit one view against another in the sources to stake out one's own position 
- Fit the material in the sources into one's own organizational framework

- Claim authorial novelty by manipulating the structure of knowledge concerning a subject matter at a certain level of complexity

In the study to be reported in the present paper, it will be seen that the above features are all found in the texts of the two high-achieving first year student participants. Compared with the previous work cited above, the present study goes beyond illuminating two successful students' epistemological stance toward their sources, i.e., their authorship strategies when writing from sources; instead, the study aims to both understand the students' beliefs about learning and writing in the university, and to link those beliefs to their approaches to writing in an introductory course of political science.

\section{Context of the Study}

Hong Kong, a former British colony located in the southern tip of East China coastline, became a Special Administrative Region of the People's Republic of China in July 1997. The English-dominant universities in Hong Kong, while continuing to be the primal targets of local secondary school graduates, in recent years have been attracting an increasing number of high-achieving students leaving secondary schools in mainland China (Sin, 2009). These mainland students apply for universities in Hong Kong mainly by virtue of their results in the National Higher Education Entrance Examination (NHEEE).

The present study was conducted in the second semester of the academic year of 2010-11 at a university in Hong Kong as part of a larger project on academic writing across disciplines. The two student participants in the present study (Jason and Ryan, both pseudonyms) were among the pool of student participants in the larger project, who were recruited on a voluntary basis. The two students knew each other and indeed shared quite a few courses they were taking in the first year. The initial purpose of the researcher's (the researcher, or the present author, is to be referred to as "I" henceforth) having interview meetings with the two was to understand their process of completing written assignments, especially in terms of the process of searching, selecting, and using sources, on a number of first year courses. However, both students frequently took initiatives during the interviews to refer to what they believed about learning and writing in the university, to explain their approaches to their assignments, to compare themselves with some of their peers in course selection, or to discuss how taking certain courses had induced changes in their thinking. I was thus motivated to pursue an understanding in, firstly, the two students' beliefs regarding learning and writing in the university, and secondly, how the beliefs may be reflected in their writing, especially in their authorship strategies when writing from sources. As both students were taking an introductory course of political science, I decided to address the second issue noted above by focusing on their essays written in response to the final assignment of the course (hereafter referred to as "the politics paper" assignment).

The inclusion of two case participants in the study would potentially provide a comparative perspective, as pointed out by some case study methodologists (Campbell, 1975; Vershuren, 2003). Jason and Ryan had both completed their secondary education in mainland China and were in the same cohort of about 200 high-achieving students (i.e., having achieved high scores in the NHEEE) admitted by the university in a recruitment exercise in the mainland. At the time of the study, their latest TOEFL scores were 115 (Jason) and 105 (Ryan) respectively out of a total of 120, with 29 (Jason) and 24 (Ryan) out of 30 in writing.

From March to April 2010, I (teaching at a Faculty from which neither student was taking any course) interviewed the two students four times each, with each meeting lasting around 30-40 minutes. Mandarin Chinese, the mother tongue shared by myself and the students, was used for all the interviews. The two students were also invited to keep process logs (with brief guidelines in the form of prompt questions provided) to document their process of preparing their politics papers. However, only Ryan produced a set of process logs (in English), while Jason's 'logs' only contained scanty reading notes. The students' drafts and readings, together with the course outline of the political science course, and the relevant lecture slides concerning the politics paper assignment were collected as far as possible and were referred to during the interviews where necessary. The dataset of the study thus consisted of the interview transcripts (translated into English), the students' papers, readings, logs (Ryan's) and notes (Jason's), and relevant course materials.

To facilitate comparison between the two students, I relied on the use of matrices (Miles \& Huberman, 1994) to tabulate and code the students' beliefs about learning and writing as expressed in the interviews. I also went through their papers and notes/logs and tabulated and coded each student's source-use strategies separately in matrices, with a view to establishing correspondences between the comments they made during the interviews (and for Ryan, also in his process logs) and their textual practices. In what follows, drawing upon the students' own voices, I will first present findings concerning the students' beliefs about learning and writing as first year 
university students, and then highlight aspects of the students' papers to illuminate how the students' beliefs about learning and writing in the university are reflected in their authorship strategies.

\section{Findings}

\subsection{Beliefs about Learning and Writing in the First Year}

Jason and Ryan's views of what they want to learn and their beliefs about what writing constitutes for first year students contrast with what may be commonly assumed about first year students. Both students stressed upon independent and critical thinking, and analytical writing with logic.

\subsubsection{Learning in the First Year}

The two students have their own perspectives upon how they should learn and what they want to learn in the university.

4.1.1.1 "I think a purpose of going to university is to let oneself become a person with independent thinking" (Jason)

Reflecting upon how he managed various courses in the first year, Jason said:

I think first of all you should learn in class, to understand what it is, then you will have your own thoughts, whether they are reasonable or not-I should say first it's an understanding process, then it's an analytical and inferential process - in this way you will reach a conclusion; basically that's a chain of processes which begins with knowing the content. (Jason)

The remarks above indicate that to Jason, the primary importance that one should attach to the understanding of lectures should be coupled with "an analytical and inferential process." His emphasis upon the latter is also seen in his expression of resistance toward economics and business subjects:

The reason I don't like economics and business is it's too down-to-earth. It teaches you- hey, you do it this way, and in the future you also do it this way in the company. To me of course there's much good stuff in it-innovation, creativity etc., but I think a purpose of going to university is to let oneself become a person with independent thinking. (Jason)

Jason explained his dislike for economics/business-related courses in terms of (in his view) a lack of space for independent thinking in these subjects (as will be seen, Ryan expressed a similar view). With the introductory courses he was taking, he explicitly regarded them as arenas for debates and for honing critical thinking skills. In the range of courses he was taking - political science, philosophy, the history of the Cultural Revolution of China, and even cognitive psychology (which was "fact-based" and aimed to "prove something through experiments and with solid evidence") - he saw "lots of debates" in all of them. Indeed, he was known to his classmates as someone who would often raise questions and challenge the professors in class (as noted by Ryan).

Jason's description of his challenging behaviors in class would indicate that he was both a diligent student and a humble learner. An example that he gave concerned how he learned to question the notion of "development" in a course on the history of the Cultural Revolution of China: at one point in class the professor pointed out that China's current Open Door Policy is similar to the country's Great Leap Movement in the 1950s (which led to wide-spread starvation) in that both aim to "develop very fast" while "ignoring the needs of the general public." Jason described how he counter-argued at that point:

I countered, saying, I think the purpose of developing the economy is no problem; what is problematic is the means of development. If you develop like the Great Leap Movement, it will be problematic; if develop like now, it may also be problematic, but development itself does not need to be questioned. "Is it true that development itself does not need to be questioned?" He [the teacher] asked, pushing my thought a step further. He said, "You think it over, is non-development necessarily bad and development necessarily good?" Then I took a step further, questioning the development itself. Question everything — the teacher's view is question everything before accepting. (Jason)

Jason admitted that such "general environment of debating" had shaped the way he wrote his assignments.

4.1.1.2 "I should learn something that is enriching at the level of spiritual culture" (Ryan)

Like Jason, Ryan prioritized critical thinking and believed this was expected in all first year courses ("the basic thing is the same, they [the courses] all teach you critical thinking"). Yet compared with Jason who seemed to focus on sharpening his argumentative edge in the first year, Ryan seemed more of a free spirit. He believed the purpose of the first year courses is to "train your learning ability, so that you can move on": 
In these courses, knowledge is not the most important thing, all these courses are at an introductory level-let you establish an ability to learn, to move on to a more advanced course. [...] Real specialization can't be achieved until you're in the Master's or PhD program. Based on this thought, I think during the undergraduate years I should learn something that is enriching at the spiritual level. (Ryan)

Like Jason, Ryan did not favor the idea of following stipulated procedures in learning; and also like Jason, he expressed strong dislike for business-related courses, in particular an accounting course in his case:

The courses that I want to take are where if you're capable enough to overthrow what the teachers have taught you, you will get an A. I don't like a course, such as accounting, where if you don't follow it [the rules taught], you are likely to fail. (Ryan)

After taking an introductory course in accounting out of curiosity, Ryan became "utterly disappointed" and decided this was not what he wanted; he wanted to take a course that "gives you a space of thinking." Both Ryan and Jason noted accounting and finance (AF) as among the most popular majors among their peers. In the observation of Ryan: "In AF what you do and where you work in the future is a clear path, while for us who study social sciences and arts, the future is uncertain." Yet still the latter was "better" to him, as he preferred something "less tangible" during his undergraduate study.

\subsubsection{Writing in the First Year}

As seen above, both students saw the primary purpose of the first year introductory courses as the training of critical thinking. Likewise, they believed in these courses what the teachers would want to see in students' writings was how you write or argue rather than what you write.

\subsubsection{1 "Your originality does not lie in your proposing a brand new viewpoint" (Jason)}

Jason said he knew his peers' perception - that they would think as first year students they are not saying anything new in their writing. He generally agreed with them on this; nevertheless, he felt the writing they were doing as first year students was still worthwhile, as writing would stimulate critical thinking:

What I write have all been written by others, and every point of mine has been written by others, so it seems we're repeating what others think. But I still think our writing is worthwhile. Critical thinking is about, above all, organizing your battling tactics of writing, and this alone is not easy. (Jason)

Thinking from the point of view of the course professors, Jason believed that "as long as you argue in a way that can be accepted by them, even if it's different from the mainstream views, they'll feel your argument is reasonable."

Jason frequently mentioned the notion of "scholarship" during the interviews. From the perspective of scholarship, he believed that originality can consist in something very small: "Your originality does not lie in your proposing a brand new viewpoint-scholarship itself is bit by bit, step by step; if you can propose something very small, it is a very useful thing at least to yourself." Referring to a cognitive psychology course, where they often needed to replicate certain experiments in class to test particular conclusions, he pointed out "this is also a kind of originality in scholarship; even though there's no addition in terms of viewpoints, it is also a kind of originality."

\subsubsection{2 "The soul of university writing is logic" (Ryan)}

Talking of writing in introductory courses, Ryan said: "The way essays should be written in these courses is the same: there is a topic, which you can criticize, or support, and you give your own opinion. This is the basic line of thinking." The rule of thumb for success in essay writing is logic, according to Ryan, for "the soul of university writing is logic." Like Jason, Ryan pointed out that the key is not what one writes, but how one writes:

Writing in the university is about learning how to write, not what to write. Above all, you should have your own clear views, and you should be able to support your views through your argument. Even if your views are ridiculous, you can use your examples and materials to make your argument zi yuan qi shuo [Chinese pinyin; literally meaning 'come to a full circle'], despite the presence of potential inadequacies. (Ryan)

From an assessor's perspective, Ryan likewise suggested "he would expect you to have a very clear point." For both Jason and Ryan the target reader of their writing was "the one who grades me," as Ryan put it. This target reader provided a dialogic partner for them to remind themselves that they should present sound arguments and follow clear logic.

How might the two students' approach to handling a written assignment in an introductory course reflect their perspectives on university learning and first year writing? In the following I will aim to provide an illustration by examining their ways of writing a politics paper assignment. 


\subsection{An Introductory Course in Political Science and the Written Assignment}

The following is an extract from the course outline of the introductory course in political science that both Jason and Ryan were taking at the time of the present study:

Being a starter for your study in the social sciences, this course is also designed to help improve your critical thinking and analytical writing skills. We hope you will become interested in our discipline and in the future you will use what you have learned in this course as a guide to further explore the exciting world of politics.

It can be seen that a stress upon the training of "critical thinking and analytical writing skills" is explicitly stated as a purpose of the course. In terms of the structure, the course consisted of an introductory session and another eleven sessions, each on a different topic. For the final paper assignment (which accounted for $40 \%$ of the final grade one would get in the course), students were expected to write on a topic of their choice from the lists of review questions provided for each session. Jason and Ryan chose two different topics, which were covered in the lectures in Week 2 (the first session following an introduction session) and Week 12 (the final session) respectively.

\subsection{Writing the Politics Paper from Sources, Writing to Achieve Authorship}

In writing their politics paper from sources, both Jason and Ryan aimed to achieve authorship.

4.3.1 "I will present it in an argument form and try to argue against the two conclusions" (Jason in the first paragraph when first drafting his paper)

The topic selected by Jason was: "Do you generally agree with modernization theory's assumptions and predictions about economic and political development across the world? If you do agree, give your reasons. If you do not agree, what is wrong with modernization theory?" The overall thrust of Jason's essay, as he put it, was to "oppose a view," or argue against the five premises and two conclusions (as synthesized by himself from reading) of the modernization theory.

4.3.1.1 Five premises and two conclusions: describing the modernization theory

On searching through the university library's online catalog (using such keywords as "modernization" and "development"), Jason found a collection of writings by A. G. Frank (Chew \& Lauderdale 2010). Jason read Chapter 1 and then found four papers cited in the chapter to read. Based on his reading and what he learned from class, he created a list of five Premises (P1-P5) and two Conclusions (C1-C2) of the modernization theory, which went into his paper under an early section called "The argument":

P1: all countries are located on a continuum of stages from underdeveloped to developed

P2: the world is evolving toward modernization

P3: development can exist wholly without the existence of underdevelopment.

P4: development is always based on the same characteristics

P5: the developed countries (developed western countries mainly) stand at the highest point of the stages

$\mathrm{C} 1$ : in the long run, all countries can achieve a state of development

C2: all countries have to adapt western developed countries' characteristics (free market, democratic political structure, protestant ethics and western culture, etc.) in order to achieve development

(From “The argument” in Jason's paper)

Before mapping out the list, in the opening paragraph of the paper he explained that providing such a list was necessary because "there is no clear-cut description of this theory [in a similar form of summary in the literature]." Following the list of premises and conclusions, in the same section Jason specified who upheld which premises (round brackets below indicating omission of references in the extract and square brackets indicating omission of texts):

All modernization scholars support one or several of the premises. Rowstow (...) upholds P1 by putting forward... P4 are held by Parsons (...), who argued that ... Lerner (...) and Inkeles (...) argued that P3 are true $[\ldots]$. Moreover, one eminent supporter of P3 is Weber (...), who argued [...]. From modernization's definition and statistical studies, P2 is true. The only problem is P5, which is not covered by scholars, but is essential for $\mathrm{C} 1$.

(From "The argument" in Jason's paper)

In the extract above, it can be seen that P2 and P5, not attributed to any particular author, indicates "an analytical and inferential process" (Jason's words quoted earlier) on Jason's part. Importantly, the extract above also shows 
that Jason did not treat the different readings in conglomeration without distinguishing between authors of varied views as the novices in Geisler's study (1991) did in writing a philosophy paper.

\subsubsection{Conflicts in the sources and mismatches between the modernization theory and the reality}

Following the section of "The argument" are two sections each with a heading, which questions the two conclusions of the modernization theory (i.e., "Modernization for all countries?" and "Western way the only way?"). In each of these two sections Jason critiqued the premises that supported the corresponding conclusion. In doing so, Jason pit the view of one author (e.g., a modernization theorist) against that of another (e.g., a critic of the modernization theory), and identified mismatches between the propositions of the modernization theory and evidence from the reality.

Then in the final paragraph of his essay, Jason proposed what he called "a revised modernization theory," which posited:

...modernization can be achieved, but developed countries have to depend on underdeveloped countries in contemporary world. Also, there are some characteristics that are results as well as incentives of the path of modernization.

(From the last paragraph of Jason's paper)

This revised version of the modernization theory, he pointed out, can powerfully explain the various phenomena discussed in the foregoing sections of the essay, in particular the reality-based evidence that mismatches the premises of the modernization theory.

4.3.1.3 "I first read, then try to understand, and then write out"

In preparing his paper Jason took brief notes while reading. For example, while reading the first chapter in Chew and Lauderdale (2010), he jotted down the following gist:

history: 1. underdeveloped countries history do not resemble developed ones, so developed countries' theories don't suit. 2. the stage of underdeveloped countries is not the same with developed countries former stage $\mathrm{p} 7$

(From Jason's notes, in English)

Jason described how he wrote from reading (he read on the computer screen):

I first read, then try to understand, and then write out. Sometimes I don't understand, and I will go back and read that part again, and write; if there's still something I don't understand, I return to reading again. But if I understand, I generally do not need to go back reading, and can just write it out. (Jason)

The importance Jason attached to understanding the readings echoed his emphasis on understanding in class. Notably, while making the comment above about understanding before writing, he also noted that this would help him "avoid plagiarism," an issue emphasized in an English enhancement course in the first semester ("we have been educated not to plagiarize") and generally warned against in the course outlines of the introductory courses, including the political science course.

4.3.2 "This essay will illustrate... how the identities are divided... and how the identity approach is utilized to interpret different political issues" (Ryan in the first paragraph of his paper).

The topic selected by Ryan was: "What is identity? Among the different explanations of the origins of social identity, which one (primordialism, constructivism and instrumentalism) appears more persuasive to you? Why? Use examples to explain." It turned out that Ryan in his paper did not discuss which of the "different explanations of the origins of social identity" "appears more persuasive." Instead, by reference to relevant lecture slides, he developed his own "division of identities" and focused on explicating how the categories in his system could "co-exist" and "help us better use the identity approach to explain political issues," as he noted in his paper.

\subsubsection{1 "This is what I call "the division of identity"}

Like Jason who found it necessary to first clarify what is modernization theory, Ryan wanted to first define his categories of identities and give them "some good names," as he said in a process log. The stages that Ryan went through to work out his "new approach" (his term in his paper) to identities were captured in his logs:

- [During class] I think the identities should be divided into different categories according to their origins and function.

- After I finish my class, I think about how to divide the identities into different categories. I think some identities exist from our birth like nationality and gender, while we get others later through different experiences and knowledge.

- [Two days later] I think again about my essay and I suddenly find that those identities that we get after birth can be divided again to two different categories, mental identities and physical identities. 
(From several entries in Ryan's process logs, in English)

Ryan's serendipitous discovery of his "theory of identity division" (his term in a process log) implied a process of critical thinking. He pointed out in the final entry of his process logs, reflecting upon the strengths of his paper: "The division of identity is totally thought out by myself and it is significant in analyzing political issues and better than the current definition of identity." The other strong point of his essay, Ryan felt, was logic, which should be the "soul" of university writing to him, as noted earlier.

\subsubsection{2 "China may be a multi-culture country but not a multi-identity country"}

In his paper, after explaining his typology of identities, Ryan had a transition paragraph before giving examples "to say how well the identity approach explains political issues" (as he explained in a process log). Below is an excerpt from the paragraph:

In my view, however, the central concern of identity approach is how a society or country can tolerate the existence of different identities, that is, whether the identity diversity can be accepted by the society and how different identities influence each other are essential to interpret political issues.

(From Paragraph 6 in Ryan's paper)

Following this bridging paragraph, Ryan wrote: "Let us use the human rights situation in China as our first example." Specifically, he cited the story of Ai Weiwei, an artist and political activist in China (very much in the news in Hong Kong at the time when Ryan was writing the politics paper), noting that Ai's case "raised another wave of discussion of the human rights situation in China after Liu Xiaobo [also a political activist in China] received the Nobel Peace Prize in 2010." In capturing Ai's story Ryan cited two references, a CNN interview with Ai available on YouTube, and a report on Ai in The Washing Post. Then he presented his view:

Whether a country can be looked as a democratic country could be determined by whether a country can accept different identities. The totalitarianism in China plays a role not only in political power but also in forming people's identities. China may be a multi-culture country but not a multi-identity country. [...] Both the case of Liu Xiaobo and Ai Weiwei reveal that China is a country in which the co-existence of different identities is not allowed and any opposite opinion can not survive under the pressure of the main ideology.

(From Paragraph 8 in Ryan's paper)

Given that Ryan had received all his previous education in mainland China (and having long been immersed in an ideology different from what seems demonstrated in the text above) before coming to his university in Hong Kong, his scathing criticism of the politics in the mainland is striking. It would not be too far-fetched to suggest that this critical edge echoes Ryan's beliefs that in the university he should aim to "learn something that is enriching at the spiritual level" and his writing should be based on critical thinking. It is worth noting that Ryan said if he were studying at a university in the mainland, he would not have held so strongly to such anti-government views, and he would not have felt free to express them.

\subsubsection{3 "I select the information I want by my essay topic"}

If Jason's processing of his sources focused on understanding and looking for contradictions and mismatches, Ryan was on the lookout for the evidence that he needed for his essay topic from the beginning. Before the lecture session on the topic of identity, Ryan went through an assigned reading (a case report), and thought to himself that if he would use the topic for his assignment, the case could be cited as an example. During the lecture he took detailed notes and paid particular attention when the professor "talked about the definition of the identity in politics" (as he noted in his logs). After deciding to use the case of Ai Weiwei as one of the examples to illustrate the value of his own version of identities in analyzing political issues, he watched YouTube videos on Ai. He likewise approached the video source from the perspective of his topic; he reported in a log: "I select the information I want by my essay topic. What I am interested in is how the identities are shown in Ai Weiwei when he conducts a series of activities to speak out the truth for the public."

Ryan further noted: "When I use the sources from readings or videos, I transform them into my own words." Apparent here of course was also awareness against plagiarism, as was the case with Jason noted earlier. On the whole, like Jason, clearly Ryan was not blindly retelling information from sources. They selected their material with a critical eye, in light of their own organizational frameworks for their essays.

\section{Discussion}

Rather than providing statistical evidence based on surveys among a sizable population of students, in the study reported above I adopted a naturalistic qualitative methodology to look closely at the case of two students, to understand their perspectives and textual practices. Specifically, two Chinese students' beliefs about learning and 
writing in the university are featured and how these were reflected in the way they wrote from sources in an essay assignment in an introductory course of political science is demonstrated.

The two students, Jason and Ryan, had much in common: they valued independent and critical thinking as the core of undergraduate education, they prioritized logic and reason as the core of university writing, they preferred subjects that encourage debates and provide no ready answers, and they desired following their own interests and treading a path that is less than certain. In writing their politics papers they engaged with their sources in ways that enabled them to propose a modified 'theory' on their topic: Jason on the modernization theory and Ryan on the division of identities which he used as a lens for analyzing political issues. But the two students also contrasted in certain ways: Jason seemed to be more focused on sharpening the argumentative edge of his mind both in class and in writing while Ryan seemed to demonstrate more of a free spirit; in building voices of authorship into their papers, Jason synthesized a wide range of sources, pitting one source against another and seeking mismatches between the modernization theory and the reality, while Ryan began with his version of identity typology, citing current political issues for its illustration and using it as a tool to make sharp criticism of the human rights situation in China.

To both students what one writes in an assignment in an introductory course is less important than how one writes - that one should write with logic and demonstrate critical thinking. Their perspective on what is expected in a first year introductory course writing assignment seemed to have served them well in the sense that they were not prohibited by a thought that they should speak like a political scientist (or a philosopher or a cognitive psychologist); instead, they focused on getting their argument across to the target reader (the teacher), while at the same time, they actually practiced speaking like a political scientist, by proposing a "revised modernization theory" (Jason) or a "new theory of identity" (Ryan). The "novice-as-expert" paradox (insightfully discussed by Sommers and Saltz (2004) has not become a source of frustration for the two students; instead, it integrated well with their beliefs about learning and writing in the university. Indeed, as Sommers and Saltz (2004) have found with first year students, it is those who embrace their first year status (as did Jason and Ryan) and who are willing to struggle through their writing tasks that are most likely to develop a sustainable interest in writing and to move forward with their learning through writing.

Jason and Ryan's case contrasts with the description of inexperienced university student writers in the literature (e.g., Geisler, 1991; Nelson \& Hayes, 1988). And their case also poses an anti-thesis to the stereotypes of 'Chinese learners' referred to at the beginning of the paper. Notably, Ryan criticized the politics in mainland China in striking terms (e.g., with such phrasings as "the totalitarianism in China" and "China is a country in which the co-existence of different identities is not allowed"), a stance he would not have taken if he were studying in a mainland university, as he admitted. From this perspective, transitioning from secondary education in mainland China to tertiary education in Hong Kong has transformed Ryan's political outlook. So was the case with Jason, when he was prompted in class to critique contemporary China's Open Door Policy, and to re-think the meaning of "development." Such transformation provides evidence that "local, situationally based cultures of learning" (Gieve \& Clark, 2005, p. 274), such as the culture of learning found in a university in Hong Kong, or even the culture of learning within an introductory first year course, powerfully shapes a (Chinese or otherwise) student's development.

\section{Conclusion}

As a qualitative case profile of two students, the present study was exploratory in nature. Nevertheless, the study echoes a long-standing call in the literature for charting in naturalistic environment "the elements that support students' performance as they work at becoming self-regulated learners in a certain domain" (Simpson \& Nist, 1997, p. 365). The study suggests that availing (learning-assisting) (Muis, 2004) beliefs about learning and writing in the university, as those held by the two case students in the study, are among such "elements" that support students' self-regulated development in the first year, and possibly in the entire course of undergraduate education.

Naturally, as the researcher, I have wondered why Jason and Ryan held those beliefs that they held? In particular, what in their previous education may have led to their availing beliefs about learning and writing in the university? I also marveled at their capability of "wrestling with complex issues" (Brownlee et al. 2009, p. 611) and of deploying sophisticated authorship strategies in writing, all in the medium of English as a second language, at a time when they had only started to extensively read English academic papers and write English essays not too long ago, as Year 1 Semester 2 students.

These puzzles can potentially be addressed by conducting longitudinal research with individual students using a literacy-as-social-practice approach, as Harklau (2001) did in studying the school-university transition experience of a group of minority students in the US. Longitudinally investigating students' beliefs about and practices in learning and reading/writing as social practices embedded in particular sociocultural contexts (Ivanič 
et al., 2009; Lea \& Street, 1998) will deepen our understanding of students' development as self-regulated learners and inform pedagogical interventions. The study reported in this paper has presented a snapshot in the unfolding of this longitudinal process.

\section{References}

Abasi, A. R., Akbari, N., \& Graves, B. (2006). Discourse appropriation, construction of identities, and the complex issue of plagiarism: ESL students writing in graduate school. Journal of Second Language Writing, 15(2), 102-117. http://dx.doi.org/10.1016/j.jslw.2006.05.001

Baynham, M. (1999). Double-voicing and the scholarly "I": On incorporating the words of others in academic discourse. Text, 19(4), 485-504. http://dx.doi.org/10.1515/text.1.1999.19.4.485

Biggs, J. B. (1999). Teaching for quality learning at university. Buckingham, UK: Open University Press.

Brownlee, J., Walker, S., Lennox, S., Exley, B., \& Pearce, S. (2009). The first year university experience: Using personal epistemology to understand effective learning and teaching in higher education. Higher Education, 58(5), 599-618. http://dx.doi.org/10.1007/s10734-009-9212-2

Cadman, K. (1997). Thesis writing for international students: A question of identity? English for Specific Purposes, 16(1), 3-14.

Campbell, D. T. (1975). "Degrees of freedom" and the case study. Comparative Political Studies, 8(2), 178-193.

Cano, F. (2005). Epistemological beliefs and approaches to learning: Their change through secondary school and their influence on academic performance. British Journal of Educational Psychology, 75(2), 203-221. http://dx.doi.org/10.1348/000709904X22683

Chan, C. K. K., \& Rao, N. (Eds.). (2009). Revisiting the Chinese learner: Changing contexts, changing education. Hong Kong: Comparative Education Research Centre, University of Hong Kong.

Chew, S. C., \& Lauderdale, P. (Ed.) (2010). Theory and methodology of world development: The writings of Andre Gunder Frank. Basingstoke: Palgrave Macmillan. http://dx.doi.org/10.1057/9780230108509

Clark, R., \& Gieve, S. N. (2006). On the discursive construction of 'the Chinese learner'. Language, Culture and Curriculum, 19(1), 54-73. http://dx.doi.org/10.1080/07908310608668754

Connor, U., \& Kramer, M. G. (1995). Writing from sources: Case studies of graduate students in business management. In D. Belcher \& G. Braine (Eds.), Academic writing in a second language: Essays on research and pedagogy (pp. 155-182). Norwood, NJ: Ablex.

Geisler, C. (1991). Toward a sociocognitive model of literacy: Constructing mental models in a philosophical conversation. In C. Bazerman \& J. Paradis (Eds.), Textual dynamics of the professions (pp.171-190). Madison, WI: The University of Wisconsin Press.

Gieve, S., \& Clark, R. (2005). "The Chinese approach to learning": Cultural trait or situated response?. System, 33(2), 261-276. http://dx.doi.org/10.1016/j.system.2004.09.015

Greene, S. (1993). The role of task in the development of academic thinking through reading and writing in a college history course. Research in the Teaching of English, 27(1), 46-75.

Greene, S. (1995). Making sense of my own Ideas. Written Communication, 12(2), 186-218. http://dx.doi.org/10.1177/0741088395012002002

Grimshaw, T. (2007). Problematizing the construct of 'the Chinese learner': Insights from ethnographic research. Educational Studies, 33(3), 299-311. http://dx.doi.org/10.1080/03055690701425643

Harklau, L. (2001). From high school to college: Student perspectives on literacy practices. Journal of Literacy Research, 33(1), 33-70. http://dx.doi.org/10.1080/10862960109548102

Hayes, N., \& Introna, L. D. (2005). Cultural values, plagiarism, and fairness: When plagiarism gets in the way of learning. Ethics \& Behavior, 15(3), 213-231. http://dx.doi.org/10.1207/s15327019eb1503_2

Holliday, A. (1999). Small cultures. Applied Linguistics, 20(2), 237-264. http://dx.doi.org/10.1093/applin/20.2.237

Higgins, L. (1993). Reading to argue: Helping students transform source texts. In A. M. Penrose and B. M. Sitko (Eds.), Hearing ourselves think: Cognitive research in the college writing classroom (pp. 70-101). New York: Oxford University Press.

Ivanič, R., Edwards, R., Barton, D., Martin-Jones, M., Fowler, Z., Hughes, B., . . Smith, J. (2009). Improving learning in college: Rethinking literacies across the curriculum. London \& New York: Routledge. 
Kaufer, D. S., \& Geisler, C. (1989). Novelty in academic writing. Written Communication, 6(3), 286-311. http://dx.doi.org/10.1177/0741088389006003003

Lavelle, E., \& Zuercher, N. (2001). The writing approaches of university students. Higher Education, 42, 373-391. http://dx.doi.org/10.1023/A:1017967314724

Lea, M.R., \& Street, B.V. (1998). Student writing in higher education: An academic literacies approach. Studies in Higher Education, 23(2), 157-172. http://dx.doi.org/10.1080/03075079812331380364

Leki, I. (2007). Undergraduates in a second language. New York: Lawrence Erlbaum Associates.

Miles, M. B., \& Huberman, A. M. (1994). Qualitative data analysis: An expanded source book (2 ${ }^{\text {nd }}$ ed.). Thousand Oaks: Sage.

Muis, K. (2004). Personal epistemology and mathematics: A critical review and synthesis of research. Review of Educational Research, 74(3), 317-378. http://dx.doi.org/10.3102/00346543074003317

Nelson, J., \& Hayes, J. R. (1988). How the writing context shapes college students' strategies for writing from sources (Technical Report No. 16). Berkeley, CA: Center for the Study of Writing.

Pajaresa, F. (2003). Self-efficacy beliefs, motivation, and achievement in writing: A review of the literature. Reading \& Writing Quarterly: Overcoming Learning Difficulties 19(2), 139- 158. http://dx.doi.org/10.1080/10573560308222

Penrose, A. M., \& Geisler, C. (1994). Reading and writing without authority. College Composition and Communication, 45(4), 505-520. http://dx.doi.org/10.2307/358762

Perry, W. (1970). Forms of intellectual and ethical development in the college years: A scheme. New York: Holt.

Pintrich, P. (2002). Future challenges and directions for theory. In B. Hofer \& P. Pintrich (Eds.), Personal epistemology: The psychological beliefs about knowledge and knowing (pp. 389-414). Mahwah, NJ: Lawrence Erlbaum Associates.

Pintrich, P. R., \& de Groot, E. V. (1990). Motivational and self-regulated learning components of classroom academic performance. Journal of Educational Psychology, 82(1), 33-40.

Schommer, M. (1993). Epistemological development and academic performance among secondary schools. Journal of Educational Psychology, 85(3), 406-411. http://dx.doi.org/10.1037/0022-0663.85.3.406

Simpson, M. L., \& Nist, S. L. (1997). Perspectives on learning history: A case study. Journal of Literacy Research, 29(3), 363-395. http://dx.doi.org/10.1080/10862969709547965

Sommers, N., \& Saltz, L. (2004). The novice as expert: Writing the freshman year. College Composition and Communication, 56(1), 124-149. http://dx.doi.org/10.2307/4140684

Sin, D. (2009). Non-locals lead way in campus research slots Quota opposed for HK students. South China Morning Post. Hong Kong: May 25, 2009. p. 1.

Sternglass, M. S. (1997). Time to know them: A longitudinal study of writing and learning at the college level. Mahwah, NJ: Lawrence Erlbaum Associates.

Verschuren, P. J. M. (2003). Case study as a research strategy: Some ambiguities and opportunities. International Journal of Social Research Methodology, 6(2), 121-139. http://dx.doi.org/10.1080/13645570110106154

Watkins, D., \& Biggs, J. (Eds.). (2001). Teaching the Chinese learner: Psychological and pedagogical perspectives. Hong Kong: Comparative Education Research Centre, University of Hong Kong.

White, M. J., \& Bruning, R. (2005). Implicit writing beliefs and their relation to writing quality. Contemporary Educational Psychology, 30, 166-189. http://dx.doi.org/10.1016/j.cedpsych.2004.07.002

\section{$(\mathrm{cc}) \mathrm{BY}$}

This work is licensed under a Creative Commons Attribution 3.0 License. 